\section{Spotlight on the November 23 Issue}

\author{
Robert A. Gross, MD, PhD, FAAN \\ Editor-in-Chief, Neurology ${ }^{\circledR}$
}

Neurosonographic monitoring of 105 spontaneous cervical artery dissections: A prospective study

\section{tat}

Spontaneous cervical artery dissections (sCADs) were detected in 76 patients: 61 involved the internal carotid artery and 44 the vertebral artery, while multiple sCADs were found in 4 patients. This study suggests that most lumen changes occurred within the first few months after the initial event, but recanalization may occur even after 1 year. See p. 1864

From editorialists Tatjana Rundek and Michael Katsnelson: "If proven and validated, a neurovascular ultrasound as a noninvasive and safe technique could have an important clinical role in the follow-up and clinical decision-making for patients with sCAD."

See p. 1858

A network approach to assessing cognition in disorders of consciousness

\section{at}

Functional MRI brain activity during a silent picture-naming task may be used as an indicator of preserved capacity for awareness in patients with disorders of consciousness. These findings suggest that the completeness of the language network provides a more precise indication of cognitive status than the conventional Revised Coma Recovery Scale. See p. 1871; Editorial, p. 1860

\section{Imaging correlates of pathology in corticobasal syndrome}

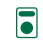

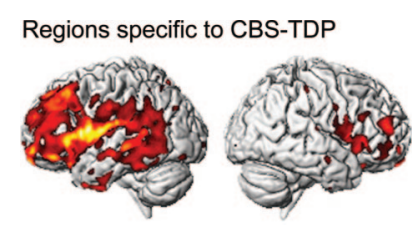

Regions specific to CBS-AD

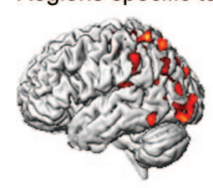

Dominant

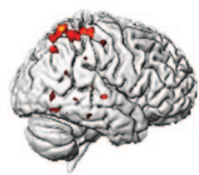

Nondominant
This paper demonstrates that imaging characteristics may

be useful in predicting underlying pathologic diagnosis in patients with corticobasal syndrome (CBS). Widespread atrophy pointed toward diagnosis of FTLD-TDP or Alzheimer disease (AD), with frontotemporal loss suggesting FTLD-TDP and temporoparietal loss suggesting $A D$, based on a comparison of 24 patients with CBS to 24 age- and gender-matched controls.

See p. 1879
The 32-year relationship between cholesterol and dementia from midlife to late life

ant

Risk factors for late-onset dementia were best identified and evaluated using life-course approaches. Higher midlife cholesterol was not related to late-onset dementia risk in 1,462 women studied over a period of 32 years; however, declining cholesterol levels from midlife to late life may be a better predictor of AD risk. See p. 1888; Editorial, p. 1862

\section{Afferent baroreflex failure in familial dysautonomia}

The authors examined afferent baroreflexes in 50 patients with familial dysautonomia and compared them to those of normal subjects and those patients with pure autonomic failure. The IKAP protein, deficient in this syndrome, is thus critical for the development of afferent baroreflex pathways; these findings have therapeutic implications in this disorder. See p. 1904

Aspiration and swallowing in Parkinson disease and rehabilitation with EMST: A randomized trial

\section{全}

This randomized trial tested 60 participants with Parkinson disease $(\mathrm{PD})$ who completed expiratory muscle strength training (EMST) for 4 weeks, 5 days per week, for 20 minutes per day, using a calibrated or sham handheld device. Swallow safety was defined by penetration-aspiration scores that improved post EMST, showing that EMST may be a restorative treatment for dysphagia. See p. 1912

Depressive symptoms in PD correlate with higher 5-HTT binding in raphe and limbic structures

The authors used PET imaging targeting the serotonin transporter and clinical scales for assessing depression in 34 patients with Parkinson disease (PD). They showed that depressive symptoms in antidepressant-naive $\mathrm{PD}$ patients correlated with relatively higher serotonin transporter binding in raphe nuclei and limbic structures, possibly reflecting lower extracellular serotonin levels.

See p. 1920

NB: Did you check out your trial issue of Neurology: Clinical Practice, which accompanied your November 2 issue of the journal? If not, please take a few minutes to look it over and provide feedback.

Podcasts can be accessed at www.neurology.org 


\title{
Neurology
}

\author{
Spotlight on the November 23 Issue \\ Robert A. Gross \\ Neurology 2010;75;1857 \\ DOI 10.1212/WNL.0b013e3181feae79
}

This information is current as of November 22, 2010

\section{Updated Information \&}

Services

Permissions \& Licensing

Reprints including high resolution figures, can be found at: http://n.neurology.org/content/75/21/1857.full

Information about reproducing this article in parts (figures,tables) or in its entirety can be found online at:

http://www.neurology.org/about/about_the_journal\#permissions

Information about ordering reprints can be found online:

http://n.neurology.org/subscribers/advertise

Neurology ${ }^{\circledR}$ is the official journal of the American Academy of Neurology. Published continuously since 1951, it is now a weekly with 48 issues per year. Copyright Copyright (? 2010 by AAN Enterprises, Inc.. All rights reserved. Print ISSN: 0028-3878. Online ISSN: 1526-632X.

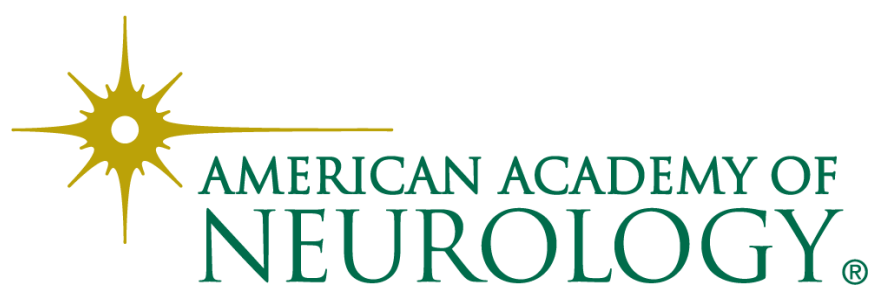

